\title{
Representações sociais do corpo: um estudo sobre as construções simbólicas em adolescentes
}

CDD. 20.ed. 616.89

796.05

\author{
Leonéa Vitória SANTIAGO* \\ Noêmia Belém de OLIVEIRA** \\ Alexandre Magno Câncio BULHÕES* \\ Antonio Carlos SIMÕES ${ }^{* * * *}$
}

*Centro de Educação,
Universidade Federal
de Alagoas.
**Instituto Superior de
Maia - Portugal.
***Escola de Educa-
ção Física e Esporte,
Universidade de São
Paulo.

\section{Resumo}

Este estudo, de natureza exploratória descritiva, buscou compreender as representações do corpo em adolescentes, do nono ano de escolaridade em Portugal em ambos os gêneros. Entrevistas foram gravadas, recorrendo-se à técnica de análise de conteúdo. Utilizou-se o programa informático NVivo para tratar os dados. Como resultado, verificamos que a herança cartesiana, concebe o corpo como extensão da mente. A representação feminina valoriza o estético, enquanto o corpo é instrumento e a saúde como valor, é representado pelo gênero masculino como forma de se estar no mundo. No lazer surge o movimento pelo movimento e de novo surge o convívio como valor. A comunicação social influência o sentido crítico de cada um. A anorexia nervosa é representada por questões socioculturais e os alunos não reconhecem a aluna diagnosticada com a patologia, no contexto escolar.

Unitermos: Educação; Educação física; Corpo; Representações sociais; Anorexia; Adolescentes.

\section{Introdução}

A maneira como os seres humanos representam o mundo adquire, na atualidade, um valor crescente. A atualidade, esta pautada por uma vertiginosa mudança, pelo imutável desejo de superação e pela constante insatisfação. Desta forma, o ser humano vê-se confrontado com a constante necessidade de se adaptar ao contexto social, uma vez que este possui vários e novos desafios. Esta mudança que caracteriza a sociedade contemporânea resulta do rápido desenvolvimento científico e tecnológico e tem como consequência a alteração da hierarquia dos valores, atitudes e comportamentos.

Em estreita relação com este cenário está a concepção de corpo, que nos últimos anos, se transformou num objeto de estudo privilegiado. Assim, vivendo numa sociedade marcada pela valorização da imagem e onde ocorre o monopólio da visão sobre os demais sentidos (Pereira, 2005), o corpo do ser humano tornou-se o seu cartão-de-visita. Aliás, parece que da sua aparência depende a sua situação no mundo (GARCIA, 1998).

O corpo passa simultaneamente a ser objeto principal e inimigo do ser humano. De fato, o que parece acontecer, quando um sujeito considera que o seu corpo não corresponde ao modelo de corpo ideal (magro, bonito, jovem, saudável e tonificado) vigente na sociedade contemporânea, tudo parece fazer para ir ao seu encontro. Desta forma, o cuidado com o corpo passa a ser concretizado num conjunto de práticas corporais, que vão desde as dietas, os exercícios físicos e as cirurgias com fins estéticos, ou seja, da aparência como um valor. Esta se configura como um estilo de vida, apreendido de diferentes modos e através de várias instâncias, durante todo o ciclo vital do ser humano. As instâncias vão desde a família, as conversas com amigos da escola e a comunicação social em geral.

$\mathrm{Na}$ verdade vivemos num tempo em que meios de comunicação social, produzem e veiculam todo um discurso sobre e para o corpo, dizendo como é que as mulheres e os homens se devem vestir comer, maquiar, divertir, mudar, comportar e até praticar exercício físico. Todas estas práticas corporais constituem um conjunto de relaçôes de saber-poder que produzem as formas de ser e de estar no mundo dos sujeitos. 
O corpo desejado torna-se então virtual, objeto de consumo e moldável através do recurso ao conhecimento científico e às novas tecnologias. Estas são apresentadas como eficientes eficazes e sem qualquer prejuízo, permitindo todo o tipo de mutação sem esforço. Esta concepção é difundida pela comunicação social, publicitando que a aproximação ao corpo ideal está acessível a todos, atribuindo deste modo a responsabilidade pela sua aquisição, unicamente ao sujeito. Surge, no entanto um problema. O modelo de corpo preconizado como ideal é praticamente impossível de alcançar.

Esta visibilidade do corpo não é nova, mas ela parece traduzir-se num imperativo cada vez mais exigente, principalmente em relação à mulher e aos jovens, que são descritos como belos, sedutores, irresponsáveis, emocionalmente problemáticos e susceptíveis a condutas 'de risco', tais como "gravidez precoce, doenças sexualmente transmissíveis, uso de drogas, desordens alimentares e sedentarismo" (DAMICO, 2007, p.96). Com a alteração da sociedade atual, surgiu um novo conceito de estilo de vida, conduzindo ao aparecimento de patologias ligadas ao sedentarismo e ao consumo. A Anorexia Nervosa é um exemplo e a sua epidemiologia, parece ser cada vez mais frequente.

A anorexia envolve uma preocupação excessiva com o peso, uma distorção da imagem corporal e um medo patológico de engordar. Segundo a AMERicAn Psychiatric Association (1996), a anorexia aparece em média aos 17 anos, com picos entre os 14 e os 18 anos de idade e mais de $90 \%$ dos casos são mulheres. Segundo Machado e GonÇALVES (2000) verifica-se uma taxa cinco vezes superior da patologia em adolescentes comparativamente a mulheres de outras faixas etárias. Quanto à prevalência nos homens, os estudos revelaram que esta é bastante inferior, sendo numa proporção entre homens e mulheres de um para nove (Coll \& QuinN, 1995).

$\mathrm{Na}$ sociedade ocidental, os casos nas mulheres jovens têm vindo a aumentar de $0,5 \%$ a $1 \%$ (APFeldorfer, 1995) e a morte surge entre 6\% a $15 \%$ dos casos, onde só o suicídio apresenta uma taxa de 5\% nos pacientes com Anorexia Nervosa crônica (Pereira, 2008). Atualmente, afigura-se uma preocupação maior.

A Anorexia Nervosa parece ganhar os contornos de um novo estilo de vida. Um estudo realizado por Pereira (2008, p.182) revelou que se corre o risco da Anorexia Nervosa se tornar uma 'condição de vida'. Segundo a autora, "nenhuma mulher nasce anorética, algumas se tornam anoréticas, mas também, outras escolhem ser anoréticas. E é precisamente para escolhê-lo ser anorética, que esta patologia parece evoluir. As páginas da internet expõem a existência de um grupo de jovens de tal forma coesas e determinadas, que atribuem à ausência de ingestão de alimentos, uma forma de superação e controle total sobre o seu corpo e sobre as suas necessidades básicas. Estas jovens só admitem no seu grupo de partilha de experiências, outras já com a patologia diagnosticada.

A área científica que serve de suporte ao nosso estudo é a Sociologia e o nosso tema, o corpo, surge devido à sua importância, utilidade, à existência de fontes e ao gosto pessoal. Segundo QueIrós (1996) as questōes sobre o corpo ganharam uma grande visibilidade e constituem nos últimos tempos, temas centrais da agenda de diversos estudos em Ciências Sociais.

Uma vez que acreditamos, que a profissão de professor de Educação Física, deve estar necessariamente, radicada nas Ciências Sociais, concordamos com Bento (1995, p.203), quando afirma que "é preciso falar do corpo, refletir sobre ele. É nele e através dele que sentimos, desejamos, expressamos e agimos. Viver é transportar a condição carnal da existência”. Desta forma, após muitas leituras e da compreensão global do tema, bem como o estudo do quadro de problemas ainda não resolvidos que serve de base para a formulação dos objetivos do nosso estudo, surge a nossa pergunta de partida: quais são as representações do corpo em adolescentes?

Fazendo uso de uma metodologia subjacente ao estudo dos conteúdos das representaçôes sociais, procurou-se responder às seguintes indagações: Quais são e como ocorrem as representações do corpo em adolescentes; Quais são e como se processam as diferenças e as semelhanças das representações do corpo nos 10 adolescentes estudados; Quais são e como se verificam as diferenças e semelhanças das representaçôes do corpo entre gêneros.

Como decorrência direta da questão orientadora isolada, durante a revisão da literatura e subjacente à estrutura metodológica, esperou neste estudo: Identificar e analisar as representaçôes do corpo de adolescentes; Conhecer e interpretar as diferenças e as semelhanças das representações do corpo nos dez alunos estudados; Encontrar e compreender as diferenças e semelhanças das representaçōes do corpo entre gêneros.

Para concretizar os objetivos deste estudo, propomo-nos estabelecer uma ligação entre o conhecimento científico e o conhecimento prático da vida do senso comum. Defendemos que esta ligação contribui com considerações para melhorar as 
intervenções pedagógicas dos professores de Educação Física, numa perspectiva de educação de um corpo social, integrado, responsável e autônomo. Desta forma, pretendemos ouvir as falas dos alunos, analisálas, interpretá-las e devolve-las como conhecimento

\section{Método}

A metodologia "é um conjunto de procedimentos inerentes ao método, que orienta cada passo de uma prática científica" (Santiago, 1999, p.15). O método é um processo formal e racional, que tem por objetivo atingir um determinado fim. Optamos pela metodologia qualitativa, uma vez que esta dá ênfase à descrição, análise e interpretação dos dados recolhidos, procura entende-los de forma contextualizada e respeita a sua riqueza, sendo fiel à forma como estes foram registrados ou transcritos. GuEDES (2002, p.18) afirma mesmo, que a metodologia qualitativa "éa única que pode tornar possível um estudo sério de todos os cenários da vida social".

Uma vez que o nosso objetivo foi recolher informações acerca dos sentidos e significados do grupo de estudo, a opção por esta metodologia afigurase como indicada. A metodologia qualitativa tem por objetivo compreender o comportamento e a experiência do ser humano, ou seja, decifrar o significado da vida humana. Indicamos, porém que utilizamos em simultâneo, alguns indicadores numéricos cujo objetivo foi o de mero apoio aos dados observados.

O método qualitativo preocupa-se com a compreensão do fenômeno estudado através da observação, descrição e interpretação do meio e do fenômeno, tal como se apresenta (ForTin, Côté \& VissandjéE, 1999). Assim sendo, podemos enquadrar o nosso estudo no tipo descritivo inserido num contexto exploratório, já que se baseia essencialmente na descrição e análise de representaçóes, sentidos e percepçóes dos alunos (FORTIN, 1999). Desta forma, o estudo descritivo e exploratório que se apresenta utilizou como enquadramento conceitual e metodológico, a Teoria das Representações Sociais e procurou dar resposta à seguinte pergunta: quais são as representaçōes do corpo em adolescentes?

Os instrumentos utilizados para a coleta dos dados foram às entrevistas semi-estruturadas que se fizeram acompanhar por um diário de campo. Optamos pela análise de conteúdo como instrumento analítico. O nosso "corpus" de estudo, é então constituído pela transcrição das entrevistas efetuadas e a técnica de tratamento das informaçôes que utilizamos foi a análise de conteúdo. do senso comum aprimorado. Consideramos este trabalho relevante, não só pelo fato de se tratar de um estudo acerca do ser e estar no mundo da vida, mas por considera o corpo como ponto de partida para qualquer conhecimento acerca do homem.

Segundo Santiago (2006), "a descrição e a interpretação coexistem e interagem durante todo o processo, pois na própria descrição está contida a interpretação". Assim, quando analisamos um texto procedemos à sua descrição, esta leva a que se assimile não só o seu conteúdo, como também a mensagem que o autor pretende transmitir.

\section{Caracterizações do grupo estudado}

Através da revisão da literatura, ampliamos o nosso conhecimento sobre o assunto em causa e definimos a população que melhor se adequava para cumprir os objetivos do nosso estudo.

Tendo em conta que o nosso estudo se dirigia a adolescentes, definimos que o nosso grupo de estudo seria constituído por alunos do Terceiro Ciclo do Ensino Básico, mais concretamente do nono ano de escolaridade, na medida em que este nível de ensino inclui jovem já com alguma capacidade de expressar a sua opinião sobre o assunto pretendido. Estes alunos já possuem alguma maturidade e capacidade que lhes permite entender e responder às questóes colocadas.

Segundo Guerra (2006, p.48), a capacidade de verbalização dos entrevistados é importante porque estes são "informadores susceptíveis de comunicar as suas percepções da realidade através da experiência vivida”. Tentou-se que as questôes fossem redigidas de forma curta, clara e precisa, com uma linguagem simples e adequada a este escalão etário, para que pudessem ser completamente compreendidas pelos alunos. Outra razão tem a ver com o fato de o nono ano ser o último ano do percurso escolar obrigatório. O que significa já terem sido vivenciadas todas as experiências obrigatórias, em nível da Área Curricular de Educação Física, para o Sistema Educativo. Ou seja, o objetivo passa então por saber "que marcas no corpo o aluno leva do Sistema Educativo” (QueIrós, 2002, p.142).

O estudo se desenvolveu mediante a realização de 10 entrevistas semi-estruturadas aos alunos, cinco alunas e cinco alunos, ou seja, os representantes e os vices representantes de cada turma. Esta escolha prendeu-se 
com o fato dos referidos alunos terem sido eleitos pelas respectivas turmas, como seus representantes. São sempre elementos dos dois gêneros, porque são estes alunos que recolhem e distribuem os objetos de valor no inicio e final de cada aula de Educação Física. Estes alunos têm idades compreendidas entre os 13 e os 17 anos (à data da realização da entrevista). Há uma turma dos alunos entrevistados que possui uma aluna diagnosticada com Anorexia Nervosa.

Dado o caráter exploratório do estudo, optamos por realizá-lo numa única escola. A escola onde, pela primeira vez, lecionamos a três anos consecutivos. Salientamos que a escola em causa situa-se num ambiente rural, pertence à Freguesia de Frazão, ao Concelho de Paços de Ferreira e ao Distrito do Porto. Criada em 1993, a escola entrou em funcionamento no ano letivo de 1993/94.

No espaço físico desportivo existe um pavilhão desportivo paroquial, campo de futebol e o pavilhão da Associação Recreativa e Cultural de Moinhos. Na escola, as instalaçôes desportivas são constituídas por pavilhão gimnoesportivo, por um poliesportivo exterior (que engloba um campo de jogos, uma caixa de saltos, uma pista de atletismo e um espaço com rede de voleibol) e por um campo de tênis. Com sala de ginástica, sala de aula, balneários e almoxarifado para o material didático, o pavilhão permite desenvolver três aulas de Educação Física em simultâneo.

\section{Procedimentos para a coleta dos dados}

Esta fase consiste segundo nos indicam QuIVY e CAmpenhoudt (2005), na construção dum instrumento capaz de recolher ou de produzir informação. Dadas as características do objeto de estudo e da sua orientação metodológica, definiram-se como instrumentos a entrevista semi-estruturada e o diário de campo. Grawitz (2001) indica que a entrevista é como um tête-à-tête, uma relação oral entre duas pessoas. Já BogdAN e BiKLEN (1994), ao definirem a entrevista, referem-na como sendo uma conversa intencional, que geralmente decorre entre duas pessoas e é dirigida por uma delas com o objetivo de obter informaçôes sobre a outra.

Estes autores indicam que, no caso de uma investigação qualitativa, a entrevista surge com um formato próprio, mas independentemente disso, a entrevista é utilizada, para recolher dados descritivos da linguagem do próprio sujeito permitindo ao investigador desenvolver intuitivamente uma ideia sobre a maneira como os sujeitos interpretam os aspectos vividos no seu dia-a-dia.
A este respeito, Lessard-Hebert, Goyette e Boutin (1994, p.160) mencionam que a entrevista é necessária quando se pretende "recolher dados válidos sobre as crenças, as opiniões e as idéias dos sujeitos observados".

Quivy e CAMPEnHOUdT (2005), vão mesmo mais longe considerando a entrevista um instrumento que garante a autenticidade e profundidade dos dados recolhidos. A entrevista coloca frente a frente entrevistador e entrevistado numa verdadeira troca: de um lado temos o entrevistado que exprime as suas percepções ou experiências de um acontecimento ou situação; do outro lado encontra-se o entrevistador que facilita essa partilha e evita que ela se afaste dos objetivos da investigação.

Uma vez que queríamos conhecer e compreender as representaçôes dos alunos acerca do corpo, julgamos que a entrevista se afigura como o instrumento mais adequado. Desta forma entrevistamos os alunos, de modo a que partilhassem conosco os seus sentimentos, as suas percepçôes e opiniōes a respeito deste tema.

As entrevistas variam quanto ao grau de estruturação, numa dimensão delimitada por dois extremos, a entrevista do tipo estruturado e a entrevista de tipo não estruturado. O tipo pelo qual optamos para a consecução do nosso estudo foi a entrevista semi-estruturada.

A entrevista semi-estruturada caracteriza-se por não ser totalmente aberta, nem por possuir um grande número de perguntas pré-determinadas. Existem algumas perguntas, sim, mas a sua ordem poderá ser alterada. O objetivo é deixar o entrevistado falar à vontade. Ao investigador cabe apenas reencaminhar a entrevista para os objetivos, cada vez que o entrevistado deles se afastar e refazer as perguntas colocadas se o entrevistado não as compreender de imediato. $\mathrm{O}$ uso desse instrumento deve ser efetuado de modo a que o comportamento do entrevistador, não induza as respostas por parte do entrevistado.

Tem como principais vantagens, a profundidade dos dados coletados, o menor tempo gasto na coleta das informaçôes e a flexibilidade. Este tipo de estrutura permite obter dados passíveis de comparação entre os vários sujeitos do estudo e segundo PARDAl e Correia (1995, p.69), é a técnica mais utilizada na "investigação social".

Ao construir a nossa entrevista, seguimos as indicaçōes de RuQuOv (1997), Quivy e CAMPENHOUDT (2005) e Silverman (2000). Assim, em primeiro lugar elaboramos um roteiro da entrevista.

$\mathrm{O}$ roteiro da entrevista foi elaborado tendo como referência a revisão da literatura, os objetivos que decorreram da pergunta de partida, a consulta de 
estudos análogos e a nossa experiência de três anos a lecionar na escola em causa. Foi estruturado em cinco grandes capítulos, contendo perguntas de 'lembrança' que apenas foram introduzidas caso os entrevistados as não referissem nas suas respostas.

O objetivo das entrevistas por nós realizadas era, sem preocupação com a ordem das questôes, introduzirem as perguntas de 'lembrança' quando oportuno, assemelhando-se a entrevista a uma conversa informal e fluida (GUERRA, 2006). Depois de elaborado o roteiro, foi aplicado, avaliado e corrigido pelos especialistas, sofrendo algumas alterações. Voltamos a aplicá-lo através da realização de "entrevistas-piloto" (MOREIRA, 1994, p.134) a alunos que não pertenciam ao grupo de estudo e que no dia, não se encontravam a realizar a aula de Educação Física a nível prático ${ }^{1}$. Posteriormente, efetuamos alguns ajustes na formulação das questôes, na nossa forma de atuar e no espaço físico. Sentimos dificuldades ao nível das questôes, porque os alunos tinham dificuldade em perceber algumas perguntas, ao nível da nossa experiência como entrevistadora, pois era ainda muito reduzida e ao nível do espaço que provocava eco e tinha muitos barulhos impossibilitando a audição posterior da entrevista. Depois de mudarmos o local da realização das entrevistas (devido ao eco), efetuarmos 34 entrevistas-piloto entre o dia 8 e o dia 18 de maio de 2008.

O roteiro da entrevista sofreu novos reajustes e por fim, elaboramos a versão final da entrevista a aplicar ao grupo de estudo. As "entrevistas-piloto" segundo Moreira (1994, p.134), têm como principal função "revelar determinados aspectos do fenômeno estudado em que o investigador não teria espontaneamente pensado por si mesmo e, assim, completar as pistas de trabalho sugeridas pelas suas leituras." Estas entrevistas não servem para verificar hipóteses, mas sim para "abrir o espírito, ouvir" (MOREIRA, 1994, p.140).

Salientamos também que, na realização deste trabalho, se encontrava a estudar no nono ano de escolaridade da escola de Frazão, uma aluna diagnosticada com Anorexia Nervosa. Esta aluna também não foi por nós entrevistada, pois uma vez que se encontrava ainda no processo de recuperação, receamos que a realização da entrevista, interferisse negativamente na sua recuperação. De forma resumida, apontamos de seguida, as fases para a coleta dos dados:

- legitimar a entrevista, motivar o entrevistado e garantir a confidencialidade das informações (dizer quais são os objetivos do estudo, explicar a sua importância, assegurar a confidencialidade dos dados e pedir autorização para fazer e gravar a entrevista), obterem os dados pessoais do entrevistado (preenchimento de uma ficha de caracterização individual) e realizar a entrevista propriamente dita.

Tivemos em conta como destacam BogDAN e BIKLEN (1994), que as boas entrevistas se caracterizam pelo fato de os sujeitos estarem à vontade e falarem livremente sobre os seus pontos de vista. Foi desta forma que colocamos as questōes, insistindo para que não tivessem vergonha de responder.

A gravação das entrevistas permite recolher na íntegra os discursos, incluindo as suas pausas e hesitações, não ficando quem investiga dependente da sua capacidade de memorização (Quivy \& CAMPENHoudT, 2005). Estas constituem os dados em bruto. A informação real e de interesse, terá de ser extraída a partir da sua transcrição (CiCCiarella, 1997).

Estas informações são fatos sociais e não simples textos, uma vez que se trata de representaçóes, pelo que são complexas (Denzin \& Lincoln, 2000). Apesar da sua complexidade, através das falas dos alunos é possível realizar inferências, sendo para isso necessário utilizar uma técnica de análise adequada. No nosso caso acreditamos ser a análise de conteúdo a técnica mais apropriada (BARDIN, 2008; DENZIL \& LinColn, 2000; VAla, 1986).

Todas as entrevistas foram transcritas de forma integral e o mais fiel possível ao que foi dito e o seu conjunto constituiu o "corpus" de estudo deste trabalho. Estas foram preparadas para serem tratadas no programa de análise de dados qualitativos NVivo versão oito. Este programa possibilita a codificação das entrevistas, uma vez que este se baseia em teorias que o suportam (Weitzman, 2000).

Antes do recurso ao programa NVivo, as entrevistas foram lidas segundo as diretrizes de GuERRA (2006, p.70), ou seja, "durante a leitura, registra na margem esquerda uma pequena síntese da narrativa (análise temática) e na margem direita a relação mais conceitual com o modelo de análise (análise problemática)". Segundo Santiago (1999, p.27), o diário de campo serve para "auxílio" e não para verificar a "veracidade do dito". O objetivo é registrar as reflexões do entrevistador, que servirão "como complemento das falas" dos alunos e descoberta de "uma relação de semelhança entre os significados das falas e as nossas representações".

Trata-se então da descrição por escrito, de todas as manifestações verbais, ações, atitudes e circunstancias físicas que se considerassem necessárias, assim como as reflexões da investigadora quando da observação do fenômeno. O "diário de campo" funciona deste modo, como reconstrução do diálogo e complemento das entrevistas (CosTA, 1986, p.132). 
É um instrumento útil, uma vez que as anotaçóes ajudarão a orientar o trabalho do investigador.

TuCKMAN (2000, p.528) defende que as notas de campo são "tão descritivas como interpretativas ou analíticas". Assim, procuramos relatar não só o que aconteceu, mas também os seus motivos através da reflexão. O diário de campo procurou ainda, registrar as nuances referentes ao processo de análise. Tratou de ser um coadjuvante da análise e não um documento a analisar. Desta forma, no diário de campo, procuramos anotar aspectos decorrentes da entrevista visto que os mesmos não podiam ser captados pelo gravador que estávamos a utilizar. Sendo assim, antes, durante e depois da realização das entrevistas fazíamos anotações a respeito do comportamento e atitudes dos entrevistados, tais como, risos (alegre, nervosos, simpático), movimentos (inquietação, atenção, dúvida) e interferências externas (sons, movimentação).

\section{Procedimentos para a análise dos dados}

$\mathrm{Na}$ organização deste estudo, de entre as várias técnicas de investigação dos conteúdos das representaçōes sociais, optou-se pela Análise de Conteúdo Temática. Neste sentido, a análise de conteúdo tem uma dimensão descritiva que visa dar conta do que nos foi narrado e uma dimensão interpretativa que decorre das interrogaçôes do analista em face de um objeto de estudo, com recurso a um sistema de conceitos teórico-analíticos cuja articulação permite formular inferências (GUERRA, 2006). Desta forma, depois de realizada a escolha dos documentos e a leitura flutuante do "corpus" de estudo, seguem-se as operações de codificação.

$O$ processo de codificação corresponde à transformação dos "dados em bruto do texto" (BARDIN, 2008, p.129) e compreende três escolhas. A escolha das unidades de análise (recorte), a escolha das regras de contagem (enumeração) e a escolha das categorias (classificação e agregação). Em relação às unidades de análise, tanto BARDIN (2008) como VALA (1986) aponta duas, a unidade de registro e a unidade de contexto.

A unidade de registro é a unidade de significação a codificar e corresponde ao segmento de conteúdo a considerar como uma unidade de base, visando a categorização e a contagem das frequências. O nível linguístico considera-se como unidade de registro a "palavra" ou a "frase", já a nível semântico, o "tema" é a unidade de registro mais utilizada (BARDIN, 2008, p.130-31). No nosso estudo optamos pelo tema, uma vez que este é geralmente utilizado para estudar, atitudes, valores e tendências.
A unidade de contexto, por sua vez, permite a compreensão da codificação da unidade de registro. "É o segmento mais largo de conteúdo que o analista examina, quando caracteriza uma unidade de registro" (VAla, 1986, p.114). No nosso caso é o parágrafo. VAla (1986, p.115) faz referência, por exemplo, de uma terceira unidade, a unidade de enumeração, que consiste numa unidade "em função da qual se procede à quantificação". O autor indica quais as unidades de enumeração podem ser de natureza geométrica e aritmética e no nosso estudo optamos pela aritmética. Esta unidade permite contar a frequência de uma categoria, a intensidade de uma atitude e o número de palavras.

As regras de enumeração são: a presença (ou ausência), a frequência, a frequência ponderada, a intensidade, a direção, a ordem, e a co-ocorrência. Assim, com o objetivo de dar um sentido um pouco mais preciso, ao nosso estudo, optamos por utilizar a frequência e a presença (ausência), uma matemática simples que não retira significado ao conteúdo. A frequência indica que quanto mais recortes tiverem as categorias, mais o que elas significam tem importância.

Segue-se então o processo de categorização. VALA (1986) indica que este processo é uma tarefa que realizamos quotidianamente com vista a reduzir a complexidade no meio ambiente, estabilizá-lo, identificá-lo, ordená-lo ou atribuir-lhe um sentido. Para BARDin (2008), a categorização é um processo de divisão das componentes das mensagens analisadas em rubricas ou categorias, uma operação de tipo estruturalista que comporta duas etapas: o inventário (isolar elementos) e a classificação (repartir os elementos, dando organização às mensagens).

A categoria é uma "rubrica significativa ou uma classe que junta, sob uma noção geral, elementos do discurso" (GuerRA, 2006, p.80). No nosso entendimento, as categorias podem ser equiparadas a pequenas gavetas que permitem uma classificação. A construção de uma grelha de análise categorial pode ser feita "a priori ou a posteriori, ou ainda através da combinação destes dois processos" (VALA, 1986, p.111). O nosso estudo combinou os dois processos. Quando às categorias construídas "a priori", o sistema categorial foi elaborado com base na revisão bibliográfica e na nossa experiência no contexto escola.

A análise do "corpus" de estudo serviu para confirmar, ou não, a existência das categorias, nas falas dos alunos. No entanto, não se colocou de parte a possibilidade de novas categorias surgirem, através da exploração das entrevistas "a posteriori". Ao longo deste procedimento, respeitamos com o maior rigor possível os princípios que presidem à construção 
do sistema categorial, a saber: a exclusão mútua, a homogeneidade, a pertinência, a objetividade e fidelidade e a produtividade.

Com o intuito de, através das falas dos alunos, conhecer e compreender "o seu modo de conduzir a própria vida” (SANTIAGO, 1999, p.28), construímos uma grelha de análise categorial, que serviu de base para a análise e interpretação dos nossos dados. Salienta-se ainda que, de todas as falas codificadas numa determinada subcategoria, elegemos as três que se mostraram mais evidentes.

\section{Análise e discussão dos dados}

A grelha de análise categorial é apresentada no quadro seguinte, assim como a indicação da frequência (colocada entre parênteses), da presença $(+)$ e ausência $(-)$, permitindo assim ter uma ideia geral da importância atribuída, por parte dos alunos do nosso grupo de estudo, a cada categoria e subcategoria. Note-se que a frequência é registrada sempre que o entrevistado se refere ao que estamos a analisar. Desta forma, a frequência não equivale ao número de alunos entrevistados.

QUADRO 1- Grelha de análise categorial.

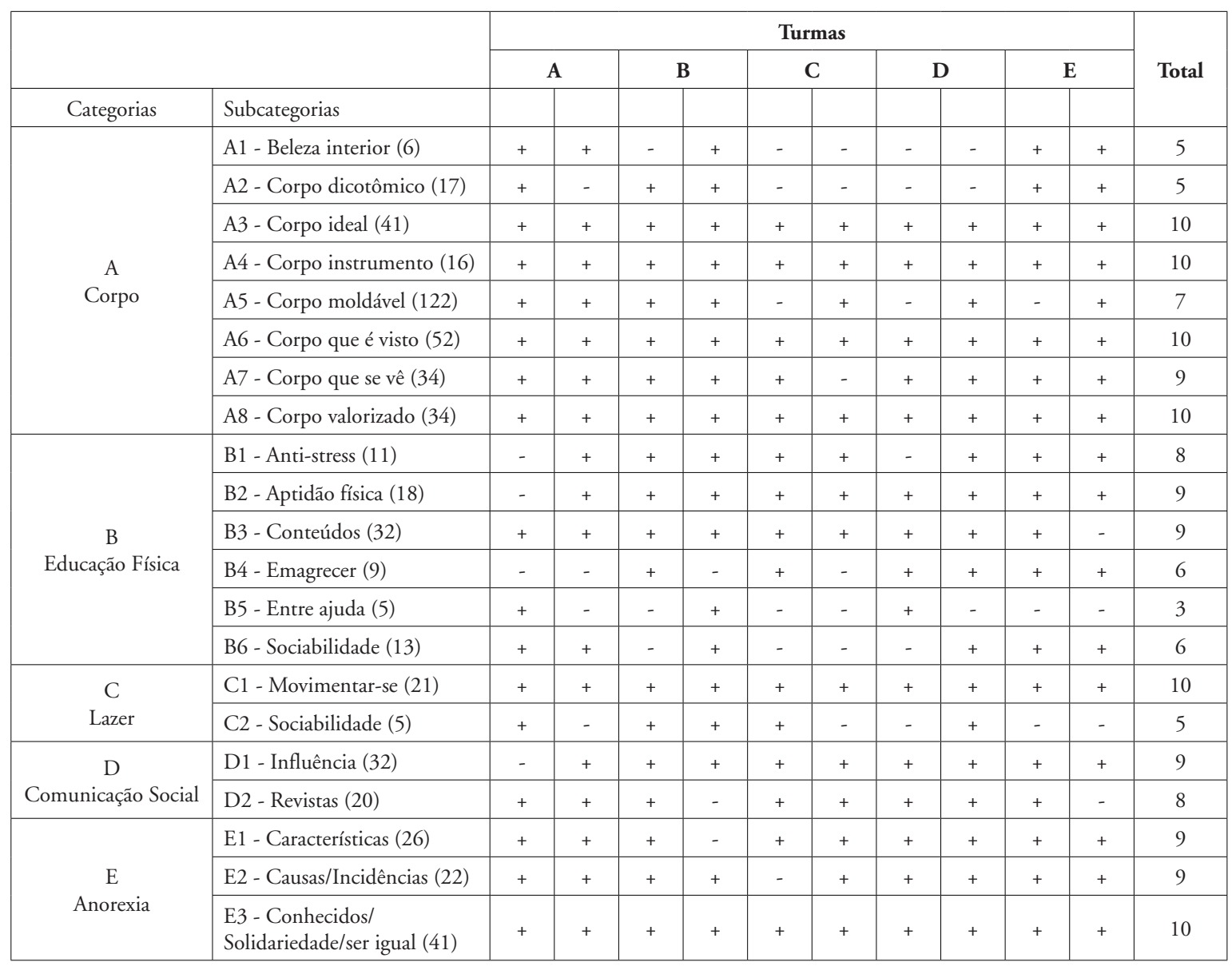

Nesse contexto, apresentamos a justificação do sistema categorial, que baseado na revisão da literatura permite fornecer alguns indicadores que fundamentam o aparecimento das referidas categorias e subcategorias. Expomos também um exemplo da fala dos alunos, codificada em cada subcategoria, de forma a melhor compreender a elaboração da nossa grelha de análise categorial.

\section{Categoria A - Corpo}

A1 - Beleza interior: embora o corpo contemporâneo eleve a aparência como valor externo em detrimento dos valores interiores do ser humano, valendo mais a sua apresentação, do que, o seu desenvolvimento intelectual, as falas contidas nesta subcategoria revelam o contrário (GERVILLA, 1993; LIPOVETSKY, 1994). 
o corpo para mim acho que, depende, o corpo não depende da aparência, acho que a aparência é uma coisa à parte é o que está fora de nós, está no exterior, o interior é que é mesmo o nosso corpo acho que, basta ter um bom corpo para conseguir fazer tudo aquilo que agente quer (E10, 9E, 14 anos, ठ̊).

A2 - Corpo dicotômico: é com Descartes que surge a concepção de corpo máquina. E uma vez as máquinas não pensam, apenas funcionam e quando avaria basta trocar as peças para voltar a funcionar, a alma passou a ocupar uma posição superior em relação ao corpo. O corpo não participa no ato de pensar (GAARDER, 1996; JANA, 1995).

é a cabeça porque é o centro do corpo, porque é, é a ela que chegam todas as informações, por exemplo, para nos movimentarmos para fazermos qualquer ato, eu acho que é a cabeça, a cabeça e também o coração porque sem o coração também não poderíamos viver, o corpo não tinha reação não podia trabalhar (E1, 9A, 16 anos, + ) $)$.

A3 - Corpo ideal: Atualmente, o sentimento de harmonia é-nos proporcionado pelo modelo de corpo que a sociedade persegue: magro, belo, jovem e tonificado. Nesta subcategoria pertencem as falas dos alunos que caracterizam a representação de corpo ideal (Correia, 2006; Pereira, 1998).

corpo elegante, se for de um homem, um pouco musculado, se for de uma mulher um pouco estreito... é, é isso (E8, 9 d, 14 anos, Ô).

Estou longe (E8, 9D, 14 anos, ठึ).

A4 - Corpo instrumento: nesta subcategoria o corpo surge numa perspectiva tecnicista. No entanto, com a crescente tecnologização, pouco a pouco, o corpo servirá apenas como suporte das funções vitais (GAARDER, 1996; JANA, 1995).

é o que podemos fazer exercício, o que nos dá para caminhar, o que nos faz andar, por exemplo, é a nossa máquina (E2, 9A, 15 anos, ठึ).

A5 - Corpo moldável: o corpo considerado ideal ultrapassa os limites da realidade biológica saudável. Mesmo assim, o ser humano recorre às atividades físicas, às cirúrgicas estéticas e às dietas, enfatizando o culto do e para o corpo (LE BRETON, 2007; LIPOVETSKY, 1989).

Não, eu acho que não, eu acho que, tou bem como estou e não, não queria melhorar nada... acho,... é mesmo gosto bem de como estou e, e não mudaria nada se pudesse mudar (E10, 9E, 14 anos, ठ̊).
Bem, eu acho que o nosso corpo vai com aquilo que nós comemos ou o exercício físico que nós fazemos (E7, 9D, 15 anos, ㅇ).

dietas não, eu até sou uma pessoa que como bem e sou assim, dietas, se fizesse uma dieta ia para anorexia ou o quê como se chama (E2, 9A, 15 anos, Ô).

Foi no ano passado, não me lembro exatamente, mas já fiz dieta (E5, 9C, 17 anos, + ).

Não muito, eu acho que, que nem mesmo as cicatrizes que eu tenho no meu corpo eu mudava, eu acho que continuava, e continuo igual (E4, 9B, 14 anos, Ô).

A6 - Corpo que é visto: o ser humano tornou-se essencialmente olhar, passando da esfera privada para a esfera pública. É precisamente através do corpo que o ser humano se apresenta os seus pares, criando-se as primeiras expectativas. É ele que facilita ou dificulta a relação com os outros (LE BrETON, 1992; RiBEIRO, 2005).

... às vezes custa ouvir certas coisas não é, mesmo que seja na brincadeira magoa muitas vezes, mas varia assim normal, aceitaria as opinióes (E1, 9A, 16 anos, + ).

Dar uma coça aos gajos (E6, 9C, 14 anos, ठે).

A7 - Corpo que se vê: Os indivíduos olham cada vez mais para si e realizam as ações em função do que o outro vai pensar ou dizer acerca do seu corpo. Até o gesto de se olhar ao espelho reflete isso mesmo (Le Breton, 2007; Lipovetsky, 1989).

sim, não gosto da minha barriga, gostava que fosse que tivesse a barriga lisinha, e acho que era só era a única coisa que se pudesse mudava (E1, 9A, 16 anos, + ).

Gosto dele, nasci assim e vou ser assim para toda a minha vida (E2, 9A, 15 anos, ठ̊).

A8 - Corpo valorizado: o corpo deixa de ser um instrumento de trabalho e passar a ser a apresentação da própria identidade, como se de um cartão-devisita se tratasse (Gomes, Silva \& QueIrós, 2000; Le Breton, 2007).

é muito importante para mim porque se, se eu não respeitar o meu corpo não, não consigo fazer nada (E6, 9C, 14 anos, ठ̊).

Dou, claro porque se a minha aparência não for boa, ninguém vai gostar de mim (E6, 9C, 14 anos, ふै). 


\section{Categoria B - Educação Física}

B1 - Anti-stress: a atividade física vale pelo prazer que dá e pela capacidade de libertar da pressão do dia-a-dia. O prazer prevalece sobre o dever, e, portanto onde o hedonismo aparece realçado. A procura do prazer, a alegria e a satisfação pessoal, fazem parte de uma atividade corporal que privilegia a relação do sujeito consigo próprio (GERVILLA, 1993; LiPOVETSKY, 1989; TOURAINE, 1994).

adoro, eu acho que, é uma das minhas preferidas para não dizer já a minha preferida, portanto é uma aula em que podemo-nos juntar, do stress de estarmos ali sentados, ter de estudar, (?) podemos fazer o que quisermos dentro daqueles limites que o professor impõe não é, de resto uma pessoa pode, pode brincar, pode soltar-se mais desde que cumpra os limites, eu acho que é a melhor aula (?) (E4, 9B, 14 anos, ठ̂).

B2 - Aptidão física: esta subcategoria rege-se pela procura da boa forma, da melhoria da condição física, da exercitação e do desenvolvimento muscular, com o intuito de adquirir o bem-estar físico.

a preparação do nosso corpo, preparar o nosso corpo que não há nas outras aulas, aqui trabalhamos o nosso corpo (E6, 9C, 14 anos, $\widehat{O}^{\lambda}$ ).

B3 - Conteúdos: aqui se encontram codificadas as falas relativas ao gosto e conteúdos da Área Curricular de Educação Física. Atualmente, o processo de ensino e aprendizagem continua a valorizar as práticas corporais mecanicistas e repetitivas impostas pelo professor, que se limita a lecionar as modalidades ditas tradicionais (Freire, 2008; Pereira, 2006). a educação física ensinou-me várias coisas novas, as regras de jogo, dos jogos e tudo (E6, 9C, 14 anos, đో).

B4 - Emagrecer: várias são as práticas disponíveis para moldar o corpo e o aproximar do corpo ideal preconizado pela sociedade atual. Nesta subcategoria encontram-se as falas que dizem respeito à utilização, ou não, dos conteúdos da aula de Educação Física com o objetivo de emagrecimento (LE BRETON, 2007; LiPOVETSKY, 1989).

Eu acho que é manter a equilibração do corpo. Para não engordamos tanto (E5, 9C, 17 anos,, ).

B5 - Entre ajuda: GERVILLA (1993) e LIPOVETSKY (1994) afirmam que a pós-modernidade é uma nova era, com novos valores e novas atitudes; CRESPO (1990) sustenta que não há uma alteração, mas sim uma inversão de valores, uma hierarquia diferente e TOURAINE (1994) defende mesmo que existe um vazio de valores. Nesta subcategoria sobressaem os discursos direcionados à entre ajuda e cooperação na aula de Educação Física).
Se algum aluno tiver algum, mais, mais dúvidas ao fazer o exercício, acho que nós ao ajudarmos, estamos a ajudar a nós próprios porque estamos a por em prática mais vezes, o que nós sabemos e estamos a ajudar o colega, porque não sabe fazer e pode ser (E7, 9D, 15 anos, ㅇ).

B6 - Sociabilidade: o grupo de amigos assegura uma identificação entre os vários elementos que o constitui e forma uma rede. Esta rede parece ser muito importante para a formação da identidade do jovem. Aqui se afiguram os discursos dos alunos em relação à importância da socialização nas aulas de Educação Física (PAIs, 1996).

gosto de fazer, faz sempre bem fazer um pouco de exercício físico ainda por cima com os nossos colegas, além de praticar um desporto estamos com os nossos colegas e, e fertilizamos a nossa amizade entre todos e acho que é bom saber fazer desporto entre amigos (E10, 9E, 14 anos, ठో).

\section{Categoria C - Lazer}

C1 - Movimentar-se: o sentido de movimento que aqui se pretende explicitar, não é o da melhoria da aptidão física. É sim o movimento pelo movimento. O caminhar, o andar de bicicleta, o jogar futebol com os amigos sem qualquer objetivo de melhoria. É o movimento simplesmente para não se estar parado. agora não, costumo andar muito a pé, assim a passear e isso, já pratiquei natação três anos, mas depois deixei, costumo andar muitas vezes de bicicleta assim mais no verão durante as férias à noite, mas assim para já não, é mais o andar a pé e prontos não faço assim mais nada (E1, 9A, 16 anos, ㅇ).

C2 - Sociabilidade: o grupo de amigos assegura uma identificação entre os vários elementos que o constitui e forma uma rede. Esta rede parece ser muito importante para a formação da identidade do jovem. O valor da socialização aqui presente refere-se ao lazer, enquanto prática extra-escola (PAIS, 1996).

Pra além de estar com amigos, não estar em casa parado em frente ao computador ou a ver

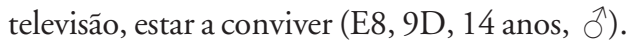

\section{Categoria D - Comunicação social}

D1 - Influência: os meios de comunicação social apelam a um modelo estético de corpo: alto magro jovem e tonificado. São vários os programas apresentados pela televisão que orientam o indivíduo a alcançar o corpo perfeito (GARCIA, 2005; QueIrós, 1996). 
é muito contagiante, claro, ouve-se sempre 'ai que me dera ter, por exemplo, uma barriga igual a não sei quantos', que é uma atriz', ai quem me dera ter uma mamas iguais aquelas', até os rapazes 'ai a barriga daqueles jogadores é só músculos', acho que é muito influenciada sim" (E3, 9B, 15 anos, ).

Eu, não muito, sinceramente não muito porque eu sou o que sou e não me quero deixar influenciar pelas outras pessoas (E6, 9C, 14 anos, ठ̂).

D2 - Revistas: na sociedade atual verifica-se a hegemonia da visão perante os restantes sentidos. São as imagens visuais que se impõem como o principal modo de dizer mensagens e não mais as palavras. Nesta subcategoria encontram-se a valorização, ou não das revistas e dos seus conteúdos, uma vez que o nosso grupo de estudo vive numa zona rural (PEREIRA, 2004). não é coisa que leia muito (E2, 9A, 15 anos, ठ̂).

Às vezes (E5, 9C, 17 anos ㅇ).

\section{Categoria E - Anorexia}

E1 - Características: a Anorexia Nervosa envolve uma preocupação excessiva com o peso, uma distorção da imagem corporal e um medo patológico de engordar. Os pacientes podem adotar métodos adicionais de perda de peso, como a auto-indução de vômitos, o uso de laxantes ou diuréticos e a prática de exercícios físicos intensos ou excessivos. A amenorréia é um dos seus indicadores e a morte, a consequência mais grave (COLl \& QuinN, 1995; Furlan, 2006).

Fica muito mau, ele é mesmo, o corpo de uma rapariga com anorexia ou até de um rapaz é pele e osso, acho que muito, até mete impressão (E9, 9E, 15 anos, + ).

Sei que pode levar à morte, se não for tratado quanto mais cedo possível, pode criar, acho que dependência, e a pessoa sofrer, desliga-se de tudo que a rodeia, fica sozinha e pode ter como consequência a morte (E8, 9D, 14 anos, ठ̋).

E2 - Incidência/Causas: o aparecimento desta doença é mais frequente no gênero feminino, as adolescentes e jovens adultas, são as que mais sofrem desta patologia. Vários fatores têm de ocorrer em conjunto, para que a Anorexia se manifeste (AlvES, VASCONCELOS \& Calvo, 2008; MaCHAdO \& GonÇALVES, 2000). eu acho que é mais nas raparigas, porque elas querem ser mais bonitas, querem conhecer mais rapazes e isso, os rapazes não são tanto, acho eu (E2, 9A, 15 anos, ふै).
Eu acho que a anorexia é uma doença devido há elevada importância que as pessoas dão á aparência do corpo (E4, 9B, 14 anos, ठึ).

E3 - Conhecidos/Solidariedade/Ser igual: nesta subcategoria encontram-se as falas referentes ao conhecimento, ou não de alguém que tenha a patologia, ao modo como se afigura a ajuda ao outro e ao querer ser igual à colega que conhecem. tenho uma amiga minha que é. Agora está fora da escola, já tem 17 anos (E6, 9C, 14 anos, ठ̂).

Não, não conheço (E9, 9E, 15 anos, ㅇ).

Tentava ajudá-la, aconselhava a falar com os pais, família, ir a um médico, para não ter de passar por isso, pelo menos sozinha (E8, 9D, 14 anos, ぶ).

Eu acho que não, acho que não, porque apesar de ter algum cuidado com a alimentação, acho que nunca vou chegar a esse nível de, de anorexia (E8, 9D, 14 anos, ठ̂).

$\mathrm{Na}$ análise e interpretação dos dados, pudemos destacar o discurso da aluna 5 (E5, 9C, 17 anos, o ) por considerarmos ser uma aluna que corre o risco de adquirir a patologia. Segundo as informaçóes que conseguimos obter através da sua diretora de turma e do seu professor de Educação física, a aluna tinha $1,70 \mathrm{~cm}$ de estatura e pesava $56 \mathrm{~kg}^{2}$. Em conversa com a diretora de turma, conseguimos saber que ao jantar, a aluna dizia que ia comer a casa de uns familiares e quando chegava a casa destes, dizia que já tinha jantado em casa dos pais.

A diretora de turma tentou controlar as refeições na cantina, através de uma folha de presenças e a aluna utilizou todo o tipo de truques para não almoçar. Desde assinar a folha de presenças e sair da cantina, dar a sua comida aos colegas, não comer e nem sequer entrar na cantina. Apresentamos então o seu discurso, sem qualquer tipo de comentários da nossa parte, uma vez que consideramos as suas palavras bastante elucidativas.

Pra mim é uma pessoa jeitosa que gosta do seu corpo, hum tem vaidade nele... Não sei, e assim essas coisas.

Apesar de o meu corpo permitir que eu queira fazer tudo, mas eu não gosto dele, eu não me sinto bem com o meu corpo.

Será que os outros gostam ou, não sei. Alguma importância.

Emagrecer. 
Para melhorar, às vezes não como tanto e tento tapar ao máximo para não perceberem.

Tipo, as modelos. Pra mim tem tudo perfeito, gosto corpo delas... tem sempre umas mamas razoáveis, umas pernas jeitosos, uma barriga... são bonitas.

\section{Longe.}

Eu acho-me gorda e elas não, acho que é nisso.

Eu por mim é a minha opinião, gosto da maneira dela e gosto do corpo dela, prontos gostava de ser, ter um corpo como o dela.

Sei lá, fugir... chorar... não sei... ( chorar $\left.^{3}\right)$.

O jeitoso e o bonito. (chorar)

Sim, influencia. (chorar).

Porque queria ser mais bonita como elas e queria ser... não sei.

Dietas já, mas... não sei.

Foi no ano passado, não me lembro exatamente, mas já fiz dieta.

Não resultou, depois eu é que deixei mesmo de, de comer o que comia antes. Não comia muito... em casa comia cereais, depois na escola só comia sopa, à tarde não comia nada e à noite comia pouco.

Porque me achava gorda, não gostava de mim.

Fiquei magra mas... os professores, os meus colegas e a minha família diziam que eu estava muito magra e assim, comecei a comer outra vez e agora acho-me outra vez gorda.

Eu acho que é manter a equilibração do corpo. Para não engordamos tanto.

Melhorar às vezes...a minha forma, não sei...e às vezes tentar esquecer o que os outros pensam ou o que acham de mim.

Vergonhaemedodoqueas outras pessoas falam demim.

Mais ou menos. Acho que são pessoas que se vêm ao espelho e acham-se gordas, por isso andam a fazer dietas malucas.

Tenho, pode não ter mais cura, pode levar à morte.
As narrativas vão de encontro com o que defende PAIs (1996) a dizer que um grupo de amigos estabelece entre si um conjunto de relações sociais efetivas, vividas, que unem os indivíduos entre si, através de laços interpessoais ou de grupo e a mudança de um qualquer sujeito provoca mudanças no grupo todo. Por sua vez, a aluna que vivenciou a patologia revela-nos que:

a pior fase... foi mesmo quando eu vinha para a escola nos inícios do oitavo ano, as pessoas olhavam para mim, ... que era o esqueleto vaidoso, he... já não aguentava e nem com os meus amigos eu queria estar porque eu sentiame diferente (16 anos, +).

Os meus amigos os meus verdadeiros amigos sabiam o que eu tinha e não ... eles sempre me apoiaram mas claro ... por fora é outra coisa que se vê (16 anos, + $)$ ).

Gostaríamos de realçar os discursos dos alunos 5 e 8 , pela sua particularidade. $\mathrm{O}$ aluno 8 acha que devido ao estado de dependência referido por CARMO (1994) a pessoa não ia ligar ao que lhe dissesse para apoiar. Por sua vez, a aluna 5 refere que preferia que se afastassem dela para que continuasse a fazer dieta.

Bom isso é que eu já não sei... porque a anorexia cria, acho que cria um estado de dependência em que a pessoa não liga muito ao que lhe dizem, só, só faz aquilo que acha melhor para si, então sinceramente não sei se ia ligar muito aquilo que eu disse (E8, 9D, 14 anos, ठ̂).

Era tentá-la ajudar, mas também era tava naquela, porque também não gosto do meu corpo e ela podia sentir aquilo que eu sinto. Se calhar ia deixar que ela se afasta-se de mim... porque nem toda a gente gosta do seu corpo, acho eu. Eu queria a continuar a fazer a mesma dieta, porque me achava gorda (E5, 9C, 17 anos, + ).

Por fim, questionamos os alunos com o objetivo de saber se achavam que lhes poderia acontecer o mesmo. Ao que eles responderam prontamente que não. Mais uma vez realçamos o sentimento contido nos discursos dos alunos 3 e 4 .

Não, ... acho que isso também era exagero, ainda de mais antes preferia ser como sou do que ser só pele e ossos, acho que assim não (E1, 9A, 16 anos,, ).

Eu acho que não, acho que não, porque apesar de ter algum cuidado com a alimentação, acho que nunca vou chegar a esse nível de, de anorexia (E8, 9D, 14 anos, ぶ). 
Não, pelo contrário, antes preferia ter mais, como se diz, um pneuzinho do que ter uma magreza brutal, como vejo muitas pessoas que têm (E10, 9E, 14 anos, ठ̂̉).

Ficar com o corpo parecido com uma anoréctica acho que nunca mesmo, porque elas ficam feias ficam com uma cara muito, muito magra com a pele muito para baixo e as mãos ficam muito secas, nota-se perfeitamente, as costas notam-se os ossos, acho que não (E7, 9D, 15 anos, ㅇ).

A anorexia é uma perturbação, cuja relação à etiológica desta perturbação, esta implica a interação complexa entre três fatores: predisponentes, precipitantes e de manutenção/perpetuação. Segundo Alves, Vasconcelos e Calvo (2008) os fatores predisponentes são aqueles que aumentam a possibilidade de aparecimento da patologia. Estes fatores podem ser psiquiátricos ou traços de personalidade (individual, familiar/hereditário e sociocultural) e são desencadeados por episódios significativos como perdas, separações, mudanças, doenças orgânicas, distúrbios da imagem corporal, depressão, ansiedade e, até mesmo, traumas de infância como abuso sexual.

$\mathrm{O}$ aluno 6 refere, em relação a uma colega que possui a patologia, que a sua causa foi devido à separação dos pais. "Acho que são os pais dela, que eles estão divorciados (E6, 9C, 14 anos, ठ̊).

Em relação aos fatores individuais, a baixa auto-estima ou auto-avaliação negativa, a obsessão, a introversão e o perfeccionismo são comuns e geralmente permanecem estáveis mesmo após a recuperação do peso corporal (ALVES, VASCONCELOS \& Calvo, 2008).

Eu nessa altura desvalorizei-me, eh eu nunca fui de ter uma auto-estima para cima foi sempre para baixo e se calhar isso também me levou a deixar de cuidar de mim (16 anos, 우).

Também existem evidências da contribuição de fatores genéticos e familiares. No que respeita aos fatores socioculturais, o padrão de beleza centrado na magreza faz parte da psicopatologia da Anorexia Nervosa. Relativamente aos fatores de manutenção/ perpetuação, são exemplo as alterações fisiológicas e psicológicas produzidas pela desnutrição.

$\mathrm{E}$ assim, pesquisar sobre as representações do corpo em adolescentes no contexto escolar permitiu-nos conhecer e compreender as suas atitudes, comportamentos e relacionamentos. Desta forma, e conforme os objetivo deste estudo, apresentaremos a interpretação dos dados sob a forma de categorias.

\section{Categoria A - Corpo}

Percebemos nos discursos dos dois gêneros, que o corpo é uma 'coisa' importante, que se deve valorizar, respeitar e preparar bem. A sua importância divide-se em dois segmentos: o corpo físico que é utilizado como instrumento para a realização das tarefas do dia-a-dia, merecendo cuidados para não ficar magoado e a aparência corporal, pois é a forma de se estar no mundo.

Ainda hoje, os alunos utilizam a expressão máquina, confirmando a herança cartesiana, que concebe o corpo como uma simples extensão da mente. Na sua concepção, o corpo serve para fazer tudo o que eles quiserem, desde realizar exercício físico, caminhar, escrever e falar. Desta forma, os alunos atribuem à mente a conotação de centro do corpo, dependendo dela, tudo o que o corpo consegue realizar. Ao corpo, coube o destino de ser apenas um instrumento que se movimenta, não participando assim no ato de pensar.

Neste nível, as representaçôes entre gêneros são iguais, o mesmo já não acontece ao nível do âmbito estético.

$O$ gênero feminino descreve o corpo ideal como sendo bonito magro e tonificado e atribui ao rosto uma particular importância. Mostra-se insatisfeito com o corpo que possui e diz que gostava de mudar. Inclusivamente indica a barriga e as pernas, como partes do corpo prioritárias a serem modificadas através de exercício físico, dietas e operações estéticas. Estas últimas realizar-se-iam, mas sem prejudicar a saúde. Dá importância à opinião dos pares, acha que essa opinião se remete à aparência corporal e a sua reação passa por chorar, deixa de comer e ficar magoado.

No gênero masculino, o corpo considerado ideal é musculado, elegante, com uma boa preparação física e com saúde. Diz que mudar o seu corpo é um aspecto que não lhe interessa, porque se sente bem com ele. Afirma que não faz dietas nem operações estéticas, porque provocam problemas de saúde. Refere não dar tanta importância à opinião dos pares e como reação prefere bater ou ignorar.

Deste modo, no gênero feminino a visibilidade aponta para o âmbito da estética, enquanto no gênero masculino aponta, também para a estética, mas a sua relevância é em nível do corpo instrumento e do corpo saudável. Ambos os gêneros consideram que o seu corpo está longe do corpo ideal e encaram a opinião dos seus amigos, que como próximos que são, é importante, positiva e construtiva.

Em relação à valorização da pessoa, não pela sua aparência, mas sim pelos seus valores interiores, 
como os sentimentos, a amizade e a entre ajuda, apresenta alguma relevância. No entanto o número de referências é baixo, levando à dedução de que este enaltecimento é pouco expressivo, predominando assim o enaltecimento dos valores da imagem do corpo.

Em suma, o discurso dos alunos revela que a sua identidade se encontra no meio do valor do ético e do valor estético. Perante esta situação, pensamos estar perante um corpo que se encontra em crise consigo e com o mundo, lutando todos os dias pela edificação de uma identidade própria conduzida por valores corporais éticos e ao mesmo tempo estéticos. Um corpo que valoriza a educação ética e moral transmitida pela família e pela escola, mas que ao mesmo tempo não pode virar as costas aos valores estéticos tão valorizados pela sociedade atual e propagados pela comunicação social. Caso o faça, corre o risco de ser descriminado pelo grupo social com quem se relaciona. Assim sendo, a imagem do corpo e os valores exteriores ganham relevância.

\section{Categoria B - Educação Física}

Globalmente, os alunos responderam que aprender as regras das modalidades tradicionais e conhecer modalidades alternativas, são os conteúdos adquiridos nas aulas de Educação Física. A forma vaga, com que os alunos se referem aos conteúdos desta Área Curricular, deixa-nos preocupados, pois deixa transparecer uma ideia de inutilidade. $\mathrm{Na}$ concepção dos alunos do nosso grupo de estudo, a Educação Física parece servir para desenvolver a aptidão física, para emagrecer e desenvolver a entre ajuda. Por outro lado, a socialização e a diminuição do "stress" adquirido nas outras Áreas Curriculares, são os aspectos que mais valorizam na aula.

Em nível do Programa Educativo de Educação Física, a aptidão física e a saúde, são os valores que suportam os conteúdos e que privilegiam a relação do indivíduo consigo próprio. Os valores referentes à ética são remetidos para segundo plano. Esta ideia reflete nas falas dos alunos, ao referirem a aptidão física como principal objetivo da aula. A procura da boa forma, da melhoria da condiçãao física, da exercitação e do desenvolvimento muscular, com o intuito de adquirir o bem-estar físico é sem dúvida, no seu entender, condição capital da aula. O outro objetivo é o emagrecimento, no entanto, este pertence apenas ao gênero feminino e apresenta poucas referências. Com menos referências ainda, encontra-se a entre ajuda, levando a pensar que o valor dado à componente estética se encontra mais presente e por isso, mais valorizada, nas falas dos jovens, que a componente ética.
No que concerne aos aspectos mais valorizados pelos jovens, na aula de Educação Física, a socialização e o libertar do "stress", são enaltecidos. Assim, os valores do convívio e do prazer prevalecem sobre o dever e surgem como os bens supremos que a aula deve proporcionar. Lembramos que procura do prazer, da alegria e da satisfação pessoal, fazem parte de uma atividade corporal que privilegia a relação do sujeito consigo próprio. Nesta categoria, não foram encontradas diferenças entre os gênero.

\section{Categoria C - Lazer}

Em relação ao lazer, o sentido de movimento que aqui se pretende explicitar, não é o da melhoria da aptidão física. É sim o movimento pelo movimento, o movimentar simplesmente para não estar parado. O caminhar, o andar de bicicleta, o jogar futebol com os amigos sem qualquer objetivo de melhoria da forma física, são as atividades realizadas após o seu horário escolar. Após a conclusão dos estudos, a sua primeira prioridade é começar a trabalhar.

O praticar exercício físico aparece de forma secundária e de novo ligado ao movimentar apenas para não estar parado. Salientamos ainda que este seria efetuada, apenas no caso da profissão exercida, fosse por eles considerada sedentária. Paralelamente ao que foi dito pelos jovens em relação à aula de Educação Física, também no lazer os seus objetivos passam essencialmente pela socialização. Assim, e de encontro com os valores dos jovens, o convívio parece ser uma grandeza muito enaltecida. Nesta categoria, também não parecem existir diferenças entre os gêneros.

\section{Categoria D - Comunicação social}

No que respeita à influência da comunicação social, tanto o gênero feminino como o gênero masculino, consideram que efetivamente esta influencia os jovens. Em relação a serem eles próprios influenciados pela comunicação social, encontramos sentidos positivos e negativos nos dois gêneros. Quanto à leitura de revistas, percebemos que de forma geral, o gênero feminino lê algumas revistas, relacionadas com a estética e a moda, enquanto o gênero masculino não lê qualquer tipo de revistas.

\section{Categoria E - Anorexia}

Nesta categoria, não se verificaram diferenças entre gêneros e ficou patente que a sua representação do corpo anoréxico, é um corpo constituído apenas por 
pele e osso. Na sua perspectiva, a pessoa olha-se ao espelho e acha-se gorda, quando efetivamente não o é. Como consequências mais graves consideram a morte. As mulheres foram consideradas como mais propensas a adquirir a patologia e esta apresenta como principal causa, os fatores de ordem psicológica. A maior parte do grupo estudado afirmou não conhecer ninguém com Anorexia Nervosa e os que afirmaram conhecer, não se referiram à aluna que frequenta a escola. Desta forma, apenas os dois alunos pertencentes à sua turma, a mencionaram. Perante a presença de uma paciente, a atitude de todo o grupo é de solidariedade, no entanto, a intensidade dos sentimentos revelados nas falas dos alunos, que pertencem à turma da aluna diagnosticada, revelou ser mais intensos. $\mathrm{O}$ mesmo acontece quando mencionam que não correm o risco de contrair a patologia. Esta percepção também é partilhada por todo o grupo de estudo.

Em suma, a herança cartesiana, que concebe o corpo como uma simples extensão da mente, permanece. A representação feminina valoriza o âmbito estético, enquanto o corpo como instrumento e a saúde como valor, é representado pelo gênero masculino como forma de se estar no mundo. O principal objetivo da aula de Educação Física éo desenvolvimento da aptidão física e em menor grau, o emagrecimento (apenas por parte do gênero feminino) e a entre ajuda. A socializaçāo e a libertação de "stress", aspectos tão importantes nos discursos atuais exteriores à escola, parecem ser também enfatizadas pelos alunos. No lazer, a ênfase surge no movimentar simplesmente para não estar parado e de novo surge o convívio como valor. A comunicação Social é fonte de grandes influências discernidas conforme o sentido crítico de cada um. Por fim, a Anorexia Nervosa é representada por questóes socioculturais e os alunos não reconhecem a aluna diagnosticada com a patologia, no contexto escolar, como tal.

Desta forma, é importante que os professores direcionem as suas práticas pedagógicas no sentido do enaltecimento dos valores interiores face aos exteriores, que, contudo não poderão ser esquecidos; da importância da Educação Física e seus conteúdos e do Paradigma da Corporeidade, que defende o ser humano como um todo.

\title{
Notas
}

1. Na escola estudada, todos os professores pedem o preenchimento de um relatório escrito aos alunos que, por motivo de saúde não podem realizar a aula prática.

2. Estes dados foram facultados pelo professor de Educação Física e pertencem ao protocolo de realização dos testes de condição física do grupo disciplinar

3. Esta indicação representa que a aluna chorou quando da realização da entrevista.

\begin{abstract}
Social representations of the body: a study on the symbolic constructions in teenagers

The current descriptive exploratory nature study aimed at understanding the representations of the body in teenagers of both sexes from the ninth school year grade in Portugal. Interviews were recorded, thus using the content analysis technique. The NVivo informatics program was used to deal with the data. The results, show that the Cartesian inheritance conceives the body as an extension of the mind. The female representation highlights aesthetics, while the body is a tool and health as value is represented by the male gender as a means of being in the world. The movement by the movement arises within the leisure and again the living appears as a value. The social communication influences each one's critical sense. The nervous anorexia is represented by social-cultural matters and the students do not recognize the student who was diagnosed with the pathology within the school context.
\end{abstract}

UnITERMS: Education; Physical education; Body; Symbolic representations; Anorexia; Adolescents. 


\section{Resumen}

Representaciones sociales del cuerpo: un estudio sobre las construcciones simbólicas en adolescentes

Este estudio, de naturaleza exploratoria descriptiva, buscó comprender las representaciones del cuerpo en adolescentes, del noveno año de escolaridad en Portugal, en ambos géneros. Entrevistas fueron grabadas, recurriéndose a la técnica de análisis de contenido. Se utilizó el programa informático NVivo para tratar los datos. Como resultado, verificamos que la herencia cartesiana, concibe el cuerpo como extensión de la mente. La representación femenina valoriza lo estético, en cuanto el cuerpo es instrumento y la salud, como valor, es representado por el género masculino como forma de estar en el mundo. En el ocio, surge el movimiento por el movimiento y de nuevo surge la convivencia como valor. La comunicación social influencia el sentido crítico de cada uno. La anorexia nerviosa es representada por cuestiones socioculturales y los alumnos no reconocen la alumna diagnosticada con la patología, en el contexto escolar.

Palabras clave: Educación; Educación física; Cuerpo; Representaciones simbólicas; Anorexia; Adolescentes.

\section{Referências}

ALVES, E.; VASCONCELOS, F.A.G.; CALVO, M.C.M. Prevalência de sintomas de anorexia nervosa e insatisfação com a imagem corporal em adolescentes do sexo feminino do Município de Florianópolis, Santa Catarina, Brasil. Cadernos de Saúde Pública, Rio de Janeiro, v.24, n.3, p.503-12, 2008.

AMERICAN PSICHIATRIC ASSOCIATION. Manual de diagnóstico e estatística das perturbaçóes mentais (DSM - IV). Lisboa: Climepsi, 1996.

APFELDORFER, G. Anorexia, bulimia, obesidade. Lisboa: Instituto Piaget, 1997.

BARDIN, L. Análise de conteúdo. Lisboa: Ediçōes 70, 2008.

BENTO, J.O. O outro lado do desporto: vivências e reflexões pedagógicas. Porto: Campo das Letras, 1995.

BOGDAN, R.; BIKLEN, S. Investigação qualitativa em educação: uma introdução à teoria e aos métodos. Porto: Porto Editora, 1994. CARMO, I. A vida por um fio: a anorexia nervosa. Lisboa: Relógio D’Água, 1994.

CICCIARELLA, C. Research in physical education, exercise science, and sport: an introduction. Scottsdalle: Gorsuch Scarisbrick, 1997.

COLL, M.; QUINN, M. Anorexia y bulimia: um problema actual. Barcelona: Colimbo, 1995.

CORREIA, C. Corpo, jovens e prática de musculação: um estudo em frequentadores de academia na região do Grande. 2006. Dissertação (Mestrado) - Faculdade de Ciências do Desporto e de Educação Física, Universidade do Porto, Porto, 2006. COSTA, A. A pesquisa de terreno em sociologia. In: SANTOS, S.A.; MADUREIRA, P.J. Metodologia das ciências sociais. Porto: Afrontamento, 1986. p.129-48.

CRESPO, J. A história do corpo. Lisboa: Difel, 1990.

DAMICO, J. O cuidado com o corpo como estratégia de sujeitos generificados. Movimento, Porto Alegre, v.13, n.1, p.93-117, 2007.

DENZIN, N.; LINCOLN, Y. Handbook of qualitative research. Thousand Oaks: Sage, 2000.

FORTÍN, M. O processo de investigação: da concepção à realização. Loures: Lusociência, 1999.

FORTÍN, M.; CÔTÉ, J.; VISSANDJÉE, B. A investigação científica. In: FORTÍN, M. O processo de investigação: da concepção à realização. Loures: Lusociência, 1999. p.15-24.

FREIRE, J. Um mundo melhor, uma outra educação física. In: RODRIGUES, D. Os valores e as atividades corporais. São Paulo: Summus, 2008. p.51-74.

FURLAN, A. Anorexia em alunas de educação física. Revista Mackenzie de Educação Física e Esporte, São Paulo, v.5, p.23-30, 2006. Número Especial.

GAARDER, J. O mundo de Sofia. Lisboa: Presença, 1996.

GARCIA, R. Lição de síntese. 1998. Tese (Agregado) - Faculdade de Ciências do Desporto e de Educação Física, Universidade do Porto, Porto, 1998. 
GARCIA, W. Corpo, mídia e representação: estudos contemporâneos. São Paulo: Thomson, 2005.

GERVILLA, E. Postmodernidad y educacion: valores y cultura de los jenes. Madrid: Dykinson, 1993.

GOMES, P.; SILVA, P.; QUEIRÓS, P. Equidade na educação: educação física e desporto na escola. Queijas: Associação

Portuguesa A Mulher e o Desporto, 2000.

GRAWITZ, M. Méthodes des sciences sociales. Paris: Dalloz, 2001.

GUEDES, L. A investigação qualitativa e a realidade existencial da escola. In: GUEDES, L. A escola e os actores: políticas e práticas. Porto: Centro de formação do SPZN, 2002.

GUERRA, I. Pesquisa qualitativa e análise de conteúdo: sentidos e formas de uso. Estoril: Principia, 2006.

JANA, J. Para uma teoria do corpo humano: apresentação e crítica da teoria do corpo humano. Lisboa: Instituto Piaget, 1995. LE BRETON, D. Anthropologie du corps et modernite. Paris: Presses Universitaires de France, 1992.

A sociologia do corpo. Petrópolis: Vozes, 2007.

LESSARD-HEBERT, M.; GOYETTE, G.; BOUTIN, B. Investigação qualitativa: fundamentos e práticas. Lisboa: Instituto Piaget, 1994.

LIPOVETSKY, G. A era do vazio. Lisboa: Relógio D`Água, 1989a.

O crepúsculo do dever: a ética indolor dos novos tempos democráticos. Lisboa: Publicaçôes Dom Quixote, 1994.

MACHADO, P.; GONÇALVES, S. Perturbaçōes do comportamento alimentar: prevenção e tratamento. In: PRECIOSO, J.; VISEU, F.; DOURADO, L.; VILAÇA, M.; HENRIQUES, R.; LACERDA, T. Educação para a saúde. Braga: Departamento de Metodologias da Investigação, Universidade do Minho, 2000. p.419-31.

MOREIRA, C. Planeamento e estratégias da investigação social. Lisboa: Instituto Superior de Ciências Sociais e Políticas, 1994. PAIS, J. Culturas juvenis. Lisboa: Imprensa Nacional/Casa da Moeda, 1996.

PARDAL, L.; CORREIA, E. Métodos e técnicas de investigação social. Porto: Areal Editores, 1995.

PEREIRA, A. Consideraçóes acerca da relação corpo e desporto numa perspectiva ecológica. 1998. Dissertação (Mestrado)- Faculdade de Ciências do Desporto e de Educação Física, Universidade do Porto, Porto, 1998.

Motricidade humana: a complexidade e a praxis educativa. 2006. Tese (Doutoramento) - Faculdade de Ciências do Desporto e de Educação Física, Universidade do Porto, Porto, 2006.

O alpinismo: uma experiencia no (pelo) corpo. Revista Portuguesa de Ciências do Desporto, Porto, v.5, n.3, p.311-21, 2005.

Para uma visão fenomenológica do corpo contemporâneo: contributo a partir do alpinismo e das ginásticas de academia. 2004. Tese (Doutoramento) - Faculdade de Ciências do Desporto e de Educação Física, Universidade do Porto, Porto, 2004. PEREIRA, C. Construindo a feminilidade na cultura da magreza: um estudo sobre corporalidade, adolescência e anorexia. In: ROMERO, E.; PEREIRA, E. Universo do corpo: masculinidades e feminilidades. Rio de Janeiro: Shape, 2008. p.165-90. QUEIRÓS, P. O corpo na educação física: uma leitura axiológica. In: PEREIRA, A.; COSTA, A.; GARCIA, R. O desporto entre lugares: o lugar das ciências humanas para a compreensão do desporto. Porto: Faculdade de Desporto/Universidade do Porto, 1996. p.173-98.

O corpo na educação física: leitura axiológica à luz de práticas e discursos. 2002. Tese (Doutoramento) - Faculdade de Ciências do Desporto e de Educação Física, Universidade do Porto, Porto, 2002.

QUIVY, R.; CAMPENHOUDT, L. Manual de investigação em ciências sociais. Lisboa: Gradiva, 2005.

RIBEIRO, A. O corpo que somos: aparência, sensualidade, comunicação. Cruz Quebrada: Casa das letras, 2005.

RUQUOY, D. Situação de entrevista e estratégia do entrevistador. In: ALBARELLO, L. Práticas e métodos de investigação em ciências sociais. Lisboa: Gradiva, 1997. p.84-116.

SANTIAGO, L. Os valores orientadores das práticas desportivas em grupos emergentes da terceira idade. In: PEREIRA, A.; COSTA, A.; GARCIA, R. O desporto entre lugares: o lugar das ciências humanas para a compreensão do desporto. Porto: Universidade do Porto/Faculdade de Desporto, 2006. p.245-63.

Os valores orientadores das práticas desportivas em grupos emergentes da terceira idade: um estudo sobre as suas construções simbólicas. 1999. Tese (Doutoramento) - Faculdade de Ciências do Desporto e de Educação Física, Universidade do Porto, Porto, 1999.

SILVERMAN, D. Analysing talk and text. In: DENZIN, N.; LINCOLN, Y. Handbook of qualitative research. Thousand Oaks: Sage, 2000. p.821-34.

TOURAINE, A. Crítica da modernidade. Lisboa: Instituto Piaget, 1994.

TUCKMAN, B. Manual de investigação em educação. Lisboa: Fundação Calouste Gulbenkian, 2000.

VALA, J. A análise de conteúdo. In: SILVA, A.; PINTO, J. Metodologia das ciências sociais. Porto: Edições Afrontamento, 1986. p.101-28. 
WEITZMAN, E. Software and qualitative research. In: DENZIN, N.; LINCOLN, Y. Handbook of qualitative research.

Thousand Oaks: Sage, 2000. p.803-20.

\begin{tabular}{r|r} 
ENDEREÇo & \\
Antonio Carlos Simões & \\
Escola de Educação Física e Esporte - USP & Recebido para publicação: 28/04/2011 \\
Av. Prof. Mello Moraes, 65 & Revisado: 14/05/2012 \\
05508-03o - São Paulo - SP - BRASIL & Aceito: 25/05/2012 \\
e-mail: acsimoes@usp.br & \\
& \\
\hline
\end{tabular}

